\title{
Effects of Pulsed Electromagnetic Fields of Different Frequencies on the Gene Expression of RANK and NFATc1 in Rat Osteoclasts Co-Cultured with Osteoblasts
}

\author{
Jian Chen*, Hui Huang, Jianquan He, Zhang Xin \\ Department of Rehabilitation, Zhongshan Hospital of Xiamen University, Xiamen University, Xiamen, China \\ Email:*chenjian5@medmail.com.cn
}

How to cite this paper: Chen, J., Huang, H., He, J.Q. and Xin, Z. (2017) Effects of Pulsed Electromagnetic Fields of Different Frequencies on the Gene Expression of RANK and NFATc1 in Rat Osteoclasts CoCultured with Osteoblasts. J. Biomedical Science and Engineering, 10, 21-30. http://dx.doi.org/10.4236/jbise.2017.101003

Received: December 26, 2016

Accepted: January 20, 2017

Published: January 23, 2017

Copyright $\odot 2017$ by authors and Scientific Research Publishing Inc. This work is licensed under the Creative Commons Attribution International License (CC BY 4.0).

http://creativecommons.org/licenses/by/4.0/ (c) (i) Open Access

\begin{abstract}
The study investigated the effects of pulsed electromagnetic fields (PEMFs) of different frequencies on the gene expression of receptor activator of nuclear factor kappa B (RANK) and Nuclear factor of activated T-cells cytoplasmic 1 (NFATc1) in rat osteoblast and osteoclast co-cultured model. Osteoblast-like cells were isolated from calvariae of Newborn Sprague Dawley rats (SD rats), while osteoclast-like cells were obtained from femora and tibiae of five weeks old SD rats. After 1 days of co-culture, the cells were exposed to premarin $\left(\mathrm{E}_{2}\right)$ and different frequencies of PEMFs ( $8 \mathrm{~Hz}$ and $16 \mathrm{~Hz}$, respectively) for 3 days. The expression of RANK and NFATc1 mRNA was analysed with realtime quantitative polymerase chain reaction. The gene expression of RANK and NFATc1 in the $E_{2}$, PEMF with $8 \mathrm{~Hz}$ and $16 \mathrm{~Hz}$ group was significantly lower than that in the control group respectively. The gene expression of NFATc1 in the PEMF with $8 \mathrm{~Hz}$ group was significantly lower than that in the control group and PEMF with $16 \mathrm{~Hz}$ group. The study indicates that PEMF with $8 \mathrm{~Hz}$ could regulate the gene expression of RANK and NFATc1 in co-cultured model.
\end{abstract}

\section{Keywords}

PEMFs, Co-Cultured, RANK mRNA, NFATc1 mRNA

\section{Introduction}

Bone through this continuous dynamic remodeling provides structural integrity, skeletal strength, and a reservoir for hematopoiesis. Two types of cells, osteoblasts and osteoclasts, maintain bone homeostasis by balancing each other's function [1] [2]. Increased osteoclast numbers and activity cause osteoporosis and periodontal disease. This bone remodeling process is regulated by numerous lo- 
cal or systemic factors, which are secreted by either osteoblast-lineage cells and influence differentiation and activity of both osteoblasts and osteoclasts or are released by osteoclasts to regulate osteoblast activity [3]. In addition, direct contacts between osteoclasts and osteoblasts via membrane-bound ligands and receptors have been proposed to contribute to the coupling between bone formation and resorption [4].

The principal regulator of bone resorption is the receptor activator of nuclear factor kappa B ligand (RANKL)/receptor activator of nuclear factor kappa B (RANK)/osteoprotegerin (OPG) pathway. The binding of RANKL to RANK stimulates the differentiation of osteoclastic precursors into osteoclasts by inducing the expression of osteoclastogenesis-specific transcription factors or by activating them. NFAT, a calcineurin- and calcium-regulated transcription factor, is a family of transcription factors originally identified in $\mathrm{T}$ cells. Nuclear factor of activated T-cells cytoplasmic 1 (NFATc1, NFAT2)-deficient embryonic stem cells fail to differentiate into osteoclasts [5]. The overexpression of constitutively active NFATc1 in bone marrow monocytes/macrophages causes precursor cells to undergo efficient differentiation even in the absence of RANKL, suggesting that NFAT2 is not only indispensable but also sufficient for osteoclastogenesis [6].

The murine co-culture assay originally described by Takahashi [7] was the first culture system developed that generated genuine, bone-resorbing osteoclasts. The use of osteoblasts and osteoclasts in co-cultures has traditionally been used to determine the relationship between the two cell types and the importance of RANKL to osteoclast differentiation [7] [8] [9].

Even though nowadays it is possible to generate osteoclasts from bone marrow cells alone by treating the cultures with RANKL and M-CSF, the co-culture system is still a useful model for studying osteoblast-osteoclast interactions and to determine the cell type affected in knock-out or transgenic mice.

Studies of the effects of PEMFs $(7.5 \mathrm{~Hz})$ on osteoclasts have indicated that PEMFs accelerate the apoptosis rate of osteoclasts derived from primary osteoblasts and bone marrow cells cocultures [10] and can regulate osteoclastogenesis, bone resorption, OPG, RANKL, and M-CSF concentrations in marrow culture system [11]. Clinical investigations further confirmed that PEMF could help enhance bone mineral density and inhibit bone loss in human patients [12] [13]. PEMFs applied at $3.8 \mathrm{mT}, 8 \mathrm{~Hz}$, and $40 \mathrm{~min}$ per day for 3 days could regulate the osteoclast-like cellic gene expression of RANK and CA II in vitro and vivo have been reported [14] [15]. In this study, we investigated the effect of pulsed electromagnetic fields of different frequencies on the gene expression of RANK and NFATc1 in rat osteoclasts co-cultured with osteoblasts and researched the molecular mechanisms underlying the effects of PEMFs on osteoclasts co-cultured with osteoblasts in vitro.

\section{Materials and Methods}

\subsection{Animals}

Newborn SD rats and five-week-old SD rats with body weights of $120-130 \mathrm{~g}$ 
were obtained from Medical College of Xiamen University Laboratory Animal Center (certificate no.2007-0005), Xiamen, China. The rats were bred essentially as previously described [14]. This study was authorized by the medical ethics committee of the Zhong Shan Hospital of Xiamen University and accord with Nation Institutes of Health guidelines regarding animal experimentation.

\subsection{Reagents and Electromagnetic Stimulation System}

The fetal bovine serum (FBS), trypsinase and penicillin-streptomycin were obtained from Gibco (USA). RANKL and M-CSF were obtained from Peprotech (USA). $E_{2}$ (premarin or conjugated $\mathrm{E}_{2}$ ) was obtained from Favor-clan HectoPalace Pharmaceutical Factory, Soochow, JiangSu, China. MEM-alpha and tris used in this study was obtained from Invitrogen Co, USA. Alkaline phosphatase (ALP) stain, Tartrate resistant Acidphos phatase (TRAP) were purchased from Technology Co, Nanjing. Alizarin Red was purchased from Sangon Biotech Co., Shanghai. The PEMF apparatus (Union-2000A osteoporosis treatment system) was purchased from the Biomedical Engineering Research Institute, Chinese Academy of Medical Sciences, Tianjin. China.

\subsection{Rat Osteoblast Cell}

Osteoblasts were obtained from calvariae of newborn Sprague-Dawley rats by a sequential enzymatic digestion as described previously [16]. Briefly, calvariae were minced and incubated at room temperature for $20 \mathrm{~min}$ with slightly shaking of an enzymatic solution containing $0.1 \%$ collagenase, $0.25 \%$ trypsin in phosphate-buffered saline (PBS, PH7.4). This procedure was repeated to yield a total of six digests. The cells isolated from the last four to six digests were cultured separately in a-modified minimum essential medium (a-MEM) containing $15 \%$ fetal calf serum (FCS). After reaching a subconfluent state $(80 \%-90 \%$ confluent), the cells were removed from each flask and combined together as osteoblasts. Cultures were incubated at $37^{\circ} \mathrm{C}$ in $5 \% \mathrm{CO}_{2}$ and the medium was changed every 3 days. Alkaline phosphatase (ALP) activity was measured by a colourimetric assay as previously described [17]. After 15 days of culture, osteoblast were fixed in 70\% cold ethanol for $1 \mathrm{~h}$ and mineralized nodules were assessed by alizarin red staining followed to the method previously described [17]. The second passage cells were used for the experiments [18].

\subsection{Rat Osteoclast-Like Cell}

Rat bone marrow cells were obtained by the method of Chen [19] with minor modifications. Osteoclast-like cells morphology, TRAP staining and the resorptive lacunae were observed as previously described [19].

\subsection{Establishment of Co-Culture System}

Osteoclast-like cells $\left(2 \times 10^{4}\right.$ cells/well $)$ cultured for 4 days were co-cultured with second-generation osteoblasts $\left(2 \times 10^{4}\right.$ cells/well $)$ in $\mathrm{D}$-minimal essential medium, containing $10 \%$ fetal bovine serum in 6 well plates. These cells were 
co-cultured in moist air at $5 \% \mathrm{CO}_{2}$ and $37^{\circ} \mathrm{C}$ for 2 days.

\subsection{Experimental Model}

In the present study, the cells in the co-culture system were equally and randomly divided into the control group (osteoclasts co-cultured with osteoblasts), $\mathrm{E}_{2}$ group (osteoclasts co-cultured with osteoblasts $+\mathrm{E}_{2}$ ), PEMF with $8 \mathrm{~Hz}$ group (osteoclasts co-cultured with osteoblasts+ PEMF with $8 \mathrm{~Hz}$ ), PEMF with $16 \mathrm{~Hz}$ group (osteoclasts co-cultured with osteoblasts+ PEMF with $16 \mathrm{~Hz}$ ). After $24 \mathrm{~h}$ of incubation, culture plates (6-well) derived from $\mathrm{E}_{2}$ group were exposed to $\mathrm{E}_{2}$ for 3 days, culture plates derived from PEMF group were exposed to different frequency of PEMF $(8,16 \mathrm{~Hz})$ for 3 days, RANK and NFATc1 mRNA were subsequently examined at the end of time points.

The intensity and time of PEMFs used in the present experiment were $3.8 \mathrm{mT}$ and 40 min per day for 3 days as used in previous studies [14], but the frequency of PEMFs was $8 \mathrm{~Hz}, 16 \mathrm{~Hz}$ respectively.

\subsection{Determination of RANK and NFATc1 mRNA Levels Using Real-Time PCR}

RANK and NFATc1 mRNA expression was analyzed by reverse transcription and polymerase chain reactions (RT-PCR) as previously described [19]. Total RNA was isolated using the TRIzol reagent according to the manufacturer's instructions (Invitrogen, USA).The primer sequences, product sizes, and condition for each gene are shown in Table 1 . The threshold cycle $(\mathrm{Ct})$ value was calculated from amplification plots [20]. $\beta$-actin was used as the housekeeping gene for normalization. The $\Delta \mathrm{Ct}$ value for each sample was obtained by subtracting the $\mathrm{Ct}$ values of a $\beta$-actin. The experiment of four samples from control group, estrogen group, $8 \mathrm{~Hz}$ group, $16 \mathrm{~Hz}$ group was performed at least three times.

\subsection{Statistical Analysis}

All data were mean values \pm SD. One-way ANOVA and the least significance difference (LSD) test were analyzed using SPSS Science. $P<0.05$ was considered significant.

\section{Results}

\subsection{Identification of Osteoblast-Like Cells}

The morphological and biochemical parameters of the cultured cells were

Table 1. The primer sequences and product size (bp).

\begin{tabular}{cccc}
\hline Primer & Sequence 5 - 3 direction & Control & Product size (bp) \\
\hline \multirow{2}{*}{ RANK } & $5^{\prime}$-CTGCTCCTCTTCATCTCTGTG-3' & $(40) 95^{\circ} \mathrm{C}, 5 \mathrm{~min} ;$ & 162 \\
& $5^{\prime}$-CTTCTGGAACCATCTTCTCCTC-3' & $95^{\circ} \mathrm{C}, 15 \mathrm{~s} ; 60^{\circ} \mathrm{C}, 60 \mathrm{~s}$ & \\
\multirow{2}{*}{ NFATc1 1} & $5^{\prime}$-CAACGCCCTGACCACCGATAG-3' & $(40) 95^{\circ} \mathrm{C}, 5 \mathrm{~min} ;$ & 392 \\
& $5^{\prime}$-GGCTGCCTTCCGTCTCATAGT-3' & $95^{\circ} \mathrm{C}, 15 \mathrm{~s} ; 60^{\circ} \mathrm{C}, 60 \mathrm{~s}$ & \\
\multirow{2}{*}{$\beta$-actin } & $5^{\prime}$-CAATTCCATCATGAAGTGTGAC-3' & $(40) 95^{\circ} \mathrm{C}, 5 \mathrm{~min} ;$ & 315 \\
& $5^{\prime}$-CCACACAGAGTACTTGCGCTC-3' & $95^{\circ} \mathrm{C}, 15 \mathrm{~s} ; 60^{\circ} \mathrm{C}, 60 \mathrm{~s}$ & \\
\hline
\end{tabular}


characterised in a preliminary study. A monolayer of spindly to spherical cells with round or elongated nuclei were formed (Figure 1(a)). ALP activity was appeared in $95 \%$ of analysed cells after $48 \mathrm{~h}$ in culture, verifying the purity of the cultures (Figure 1(b)). Alizarin red stained after 15 days in culture, appeared red calcified nodules (Figure 1(c)).

\subsection{Identification of Osteoclast-Like Cells}

As our previous study [14], the osteoclast-like cells emerged three or more nuclei and pseudofoot-like activity at day 3. TRAP-positive multinucleated cells were observed at day 4 . They were irregular or elliptical in configuration (Figure 1(d)).

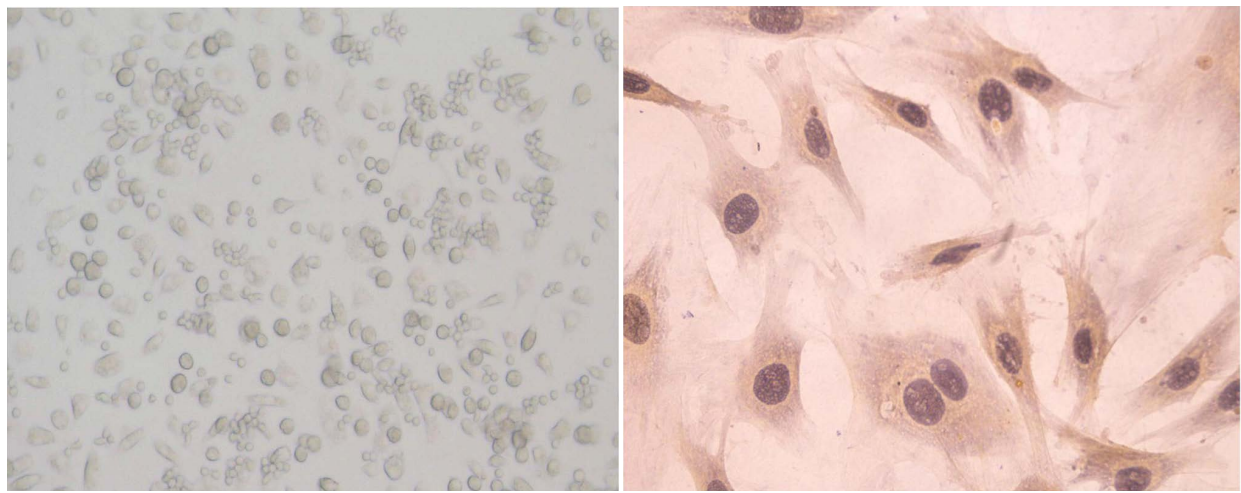

(a)

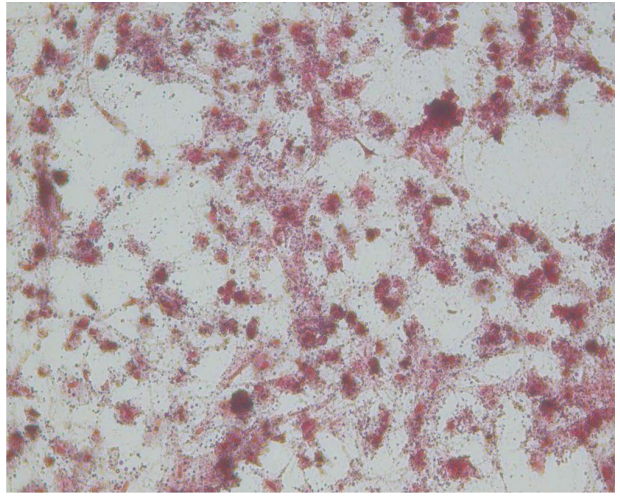

(c)

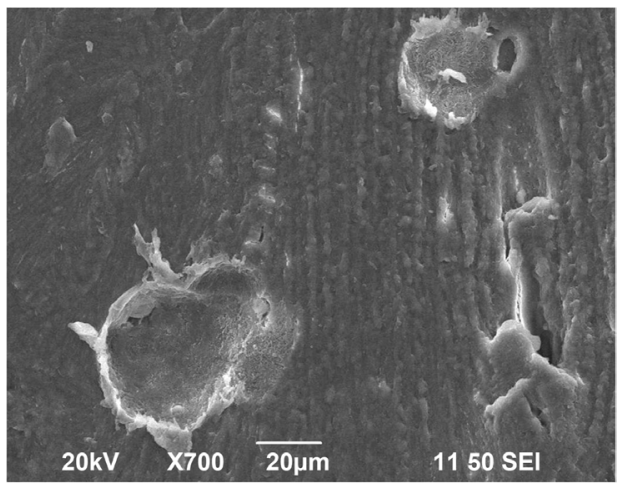

(e) (b)

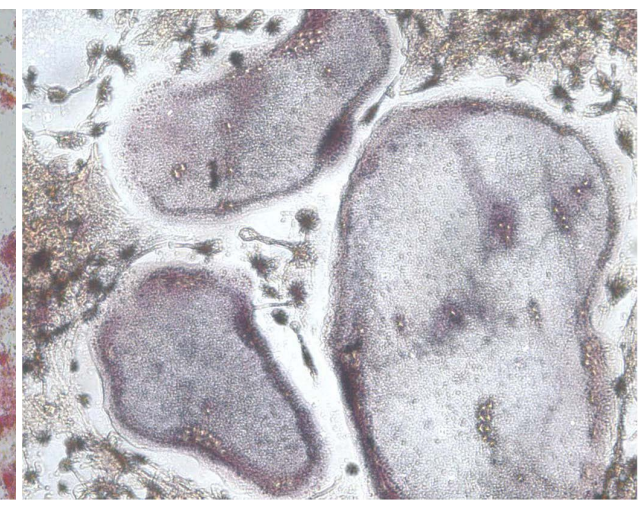

(d)

Figure 1. (a) Osteoblasts cultured at $3 \mathrm{~d}(\times 200)$. (b) ALP stained $(\times 40)$. (c) Alizarin red stained $(\times 200)$. (d) TRAP stained $(\times 100)$. (e) Scanning electron microscopic picture of lacunae $(\times 1400)$. 
In bone resorption studies, many resorption pits are observed on a bone slice cultured with bone marrow cells at day 6. These bone resorption pits were round, oval, sausage, or irregular (Figure 1(e)).

\subsection{Regulation of RANK and NFATc1 mRNA Expression}

The effect of the pulsed electromagnetic fields of different frequencies on rat osteoclasts co-cultured with osteoblasts was examined by analysing the mRNA expression of RANK and NFATc1. RT-PCR was accomplished after the high purity of the total RNA was verified and the primer design and probe synthesis were validated. The gene expression of RANK in the $\mathrm{E}_{2}$ group, PEMF with $8 \mathrm{~Hz}$ group and PEMF with $16 \mathrm{~Hz}$ group was significantly lower than that in the control group ( $P=0.000, P=0.005, P=0.017$, respectively). The gene expression of RANK in the $\mathrm{E}_{2}$ group was not statistically lower than that in the PEMF with $8 \mathrm{~Hz}$ group and PEMF with $16 \mathrm{~Hz}$ group ( $P=0.161, P=0.056$, respectively). The expression of RANK mRNA in the PEMF with $8 \mathrm{~Hz}$ group was not statistically lower than that in the PEMF with $16 \mathrm{~Hz}$ group $(P=0.562)$ also, illustrating that PEMFs with $8 \mathrm{~Hz}$ group, PEMFs with $16 \mathrm{~Hz}$ group and estrogen inhibit the expression of RANK mRNA (Figure 2(a)). The gene expression of NFATc1 in the control group was significantly higher than that in the $\mathrm{E}_{2}$ group, PEMF with 8 $\mathrm{Hz}$ group and PEMF with $16 \mathrm{~Hz}$ group $(P=0.000, P=0.000, P=0.004$, respectively), demonstrating that PEMFs and estrogen inhibit the expression of NFATc1 mRNA. The gene expression of NFATc1 in the $\mathrm{E}_{2}$ group was not statistically lower than that in the PEMF with $8 \mathrm{~Hz}$ group $(P=0.813)$. The gene expression of NFATc1 in the $\mathrm{E}_{2}$ group was significantly lower than that in the control group and PEMF with $16 \mathrm{~Hz}$ group $(P=0.000, P=0.005$, respectively). The gene expression of NFATc1 in the PEMF with $8 \mathrm{~Hz}$ group was significantly lower than that in the control group and PEMF with $16 \mathrm{~Hz}$ group also $(P=0.000, P=$ 0.008 , respectively) (Figure $2(\mathrm{~b})) .{ }^{\star} p<0.05,{ }^{*} p<0.05$.

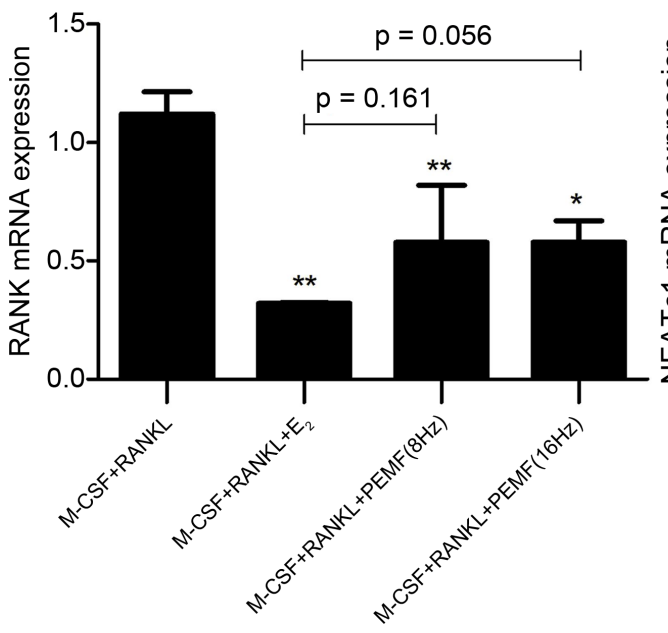

(a)

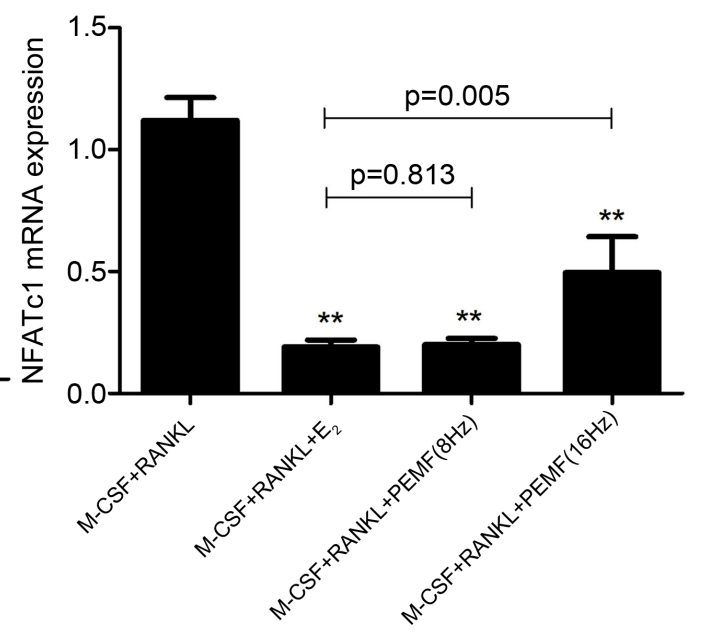

(b)

Figure 2. (a) Effect of different frequencies of pulsed electromagnetic fields on expression of RANK genes. (b) Effect of different frequencies of pulsed electromagnetic fields on expression of NFATc1 genes. 


\section{Discussion}

Osteoclasts root in bone marrow cells of the monocyte/macrophage lineage through differentiation, maturation and fusion. The receptor activator of nuclear factor kappa B ligand (RANKL) and macrophage colony-stimulating factor (M-CSF) play important roles and have been considered as indispensable for differentiation and maintenance of osteoclasts in the process. RANKL generated by osteoblasts through binding to its receptor (RANK) on osteoclast precursor cells results in activation of osteoclast and easily lead to osteoporosis. RANK stimulation affects gene expression of nuclear factor of activated $\mathrm{T}$ cells, calcineurin-dependent 1 (NFATc1) via the activator protein 1 (AP-1). Recently, A major breakthrough in osteoclast biology was the identification of NFATc1 as a main osteoclastogenic transcription factor. Takayanagi reported that NFAT2 plays an essential and sufficient role in osteoclastogenesis. They indicated that RANKL causes and motivates NFAT2 through calcium signaling. Both the transient initial release of $\mathrm{Ca}^{2+}$ from intracellular stores and the influx through specialized $\mathrm{Ca}^{2+}$ channels operate the dephosphorylation of the cytoplasmic components (NFAT2 proteins) and give rise to their nuclear localization, which is followed by the activation of osteoclast-specific genes [6].

Pulsed electromagnetic fields (PEMFs) are useful therapy for patients with delayed fracture healing and nonunions [21] [22] [23] and affect different aspects of biomolecular synthesis in cells, including the kinetics of DNA, RNA, and protein production [24] [25]. In previous studies, research has focused of the effects of PEMF on osteoblasts and osteoclasts respectively, but the proliferation and activation of $\mathrm{OC}$ in $\mathrm{OB}-\mathrm{OC}$ co-culture during PEMF stimulation has not been fully elucidated. In vivo, osteoclast and osteoblast differentiation, survival, and activity are tightly coupled, Osteoblast-lineage cells at all stages of differentiation, from pluripotent precursors to matrix-embedded osteocytes, produce regulatory factors that modulate the differentiation and activity of both osteoblasts and osteoclasts. Osteoclasts can also release factors that feed back to regulate osteoblast activity [3] [26] [27]. Therefore, the OB-OC co-culture system is much closer to the microenvironment in vivo. It have contributed to explain the interactions between osteoblasts and osteoclasts, exploring molecular communication in bone diseases [28]. Currently, there are two main types of co-culture systems: direct or indirect-contact systems. The direct-contact system is well defined, in that two types of cells are co-incubated directly in the same environment, thereby enabling synaptic connections for signal transduction. In the indirect-contact system, two types of cells are co-cultured in a common environment without touching, and their interaction is dependent on the numerous cytokines and growth factors produced by both types of cells.

In this study, the direct-contact system was used. Osteoclast-like cells showed various morphological appearances: most had irregular or elliptical configurations. TRAP staining of the osteoclast-like cells displayed uneven red deposits in the cytoplasm of these large cells. Moreover, the round, elliptical, or irregular resorptive pits excavated by the osteoclast-like cells were observed, which dem- 
onstrated the activity of these cells in the resorption experiment. Osteoblast formed a monolayer of spindle-shaped to roughly trapezoidal cells with round or elongated nuclei. ALP activity was present in $95 \%$ of analysed cells after $48 \mathrm{~h}$ in culture, confirming the purity of the cultures. Alizarin red stained after 15 days in culture, appeared red calcified nodules. We have previously found that PEMFs applied at $3.8 \mathrm{mT}, 8 \mathrm{~Hz}$, and $40 \mathrm{~min}$ per day for 3 days could modulate the osteoclast-like cellic expression of RANK and CAII mRNA in vitro and vivo. These data demonstrate that PEMFs could regulate the gene expression of CAII in ovariectomized rats [14] [15]. In this study, we investigated the effect of PEMFs on the gene expression of RANK and NFATc1 in rat osteoclasts co-cultured with osteoblasts. This study clarifies that the gene expression of NFATc1 and RANK in the $\mathrm{E}_{2}$ group and PEMFs groups was significantly lower than that in the control group $(P=0.000, P=0.000, P=0.004, P=0.000, P=$ $0.005, P=0.017$, respectively), demonstrating that $\mathrm{E}_{2}$ and PEMFs reduces the expression of NFAT2 and RANK mRNA. In addition, the expression of NFAT2 in the PEMFs with $8 \mathrm{~Hz}$ group was significantly lower than that in the PEMFs with $16 \mathrm{~Hz}$ group ( $P=0.008$, respectively).

This study has some limitations which have to be pointed out. There are lack of immunohistochemistry and wester-blot analysis of RANK and NFATc1. We acknowledge also that these are only elementary analyses on the effect of PEMFs on rat osteoclasts in a co-culture system, evaluating only the mRNA expression of RANK and NFATc1, but our preliminary results prove that different types and values of electromagnetic fields can differently influence osteoclast cells in a co-culture system. The study can be taken only as an initial evidence of the different effects of electromagnetic fields on bone tissue. Further studies on this topic are necessary to increase our comprehension on how pulsed electromagnetic fields with $8 \mathrm{~Hz}$ could influence the molecular mechanism of signal transduction in a co-culture system. In conclusion, these data revealed that PEMFs applied at $3.8 \mathrm{mT}, 8 \mathrm{~Hz}$, and $40 \mathrm{~min}$ per day for 3 days could affect the expression of RANK and NFATc1 mRNA in rat osteoclasts co-cultured with osteoblasts. Therefore, upon the predecessors' investigations, our results, we deduce that PEMFs with $8 \mathrm{~Hz}$ might regulate the process of osteoclast activation and following bone resorption in a co-culture system, at least partially, through RANK and NFATc1. Further studies on this topic are necessary to improve our understandings on how PEMFs with $8 \mathrm{~Hz}$ could affect the molecular mechanism of signal transduction in a co-culture system.

\section{Acknowledgements}

This work was supported by grants from the National Natural Science Foundation of China (grant numbers 81272168), the Natural Science Foundation of Fujian (grant numbers 2016J01623).

\section{References}

[1] Teitelbaum, S.L. (2000) Bone Resorption by Osteoclasts. Science, 289, 1504-1508. 
https://doi.org/10.1126/science.289.5484.1504

[2] Suda, T., Takahashi, N., Udagawa, N., Jimi, E., Gillespie, M.T. and Martin, T.J. (1999) Modulation of Osteoclast Differentiation and Function by the New Members of the Tumor Necrosis Factor Receptor and Ligand Families. Endocrine Reviews, 20, 345-357. https://doi.org/10.1210/edrv.20.3.0367

[3] Sims, N,A. and Walsh, N.C. (2012) Intercellular Cross-Talk among Bone Cells: New Factors and Pathways. Current Osteoporosis Reports, 10, 109-117. https://doi.org/10.1007/s11914-012-0096-1

[4] Matsuo, K. and Irie, N. (2008) Osteoclast-Osteoblast Communication. Archives of Biochemistry and Biophysics, 473, 201-209.

https://doi.org/10.1016/j.abb.2008.03.027

[5] Lee, N.K. (2010) Molecular Understanding of Osteoclast Differentiation and Physiology. Journal of Clinical Endocrinology \& Metabolism, 25, 264-269. https://doi.org/10.3803/EnM.2010.25.4.264

[6] Takayanagi, H., Kim, S., Koga, T., Nishina, H., Isshiki, M., Yoshida, H., Saiura, A., Isobe, M., Yokochi, T., Inoue, J.-I., Wagner, E.F., Mak, T.W., Kodama, T. and Taniguchi, T. (2002) Induction and Activation of the Transcription Factor NFATc1 (NFAT2) Integrate RANKL Signaling in Terminal Differentiation of Osteoclasts. Developmental Cell, 3, 889-901. https://doi.org/10.1016/S1534-5807(02)00369-6

[7] Takahashi, N., Akatsu, T., Udagawa, N., Sasaki, T., Yamaguchi, A., Moseley, J.M., Martin, T.J. and Suda, T. (1988) Osteoblastic Cells Are Involved in Osteoclast Formation. Endocrinology, 123, 2600-2602. https://doi.org/10.1210/endo-123-5-2600

[8] Jimi, E., Nakamura, I., Amano, H., Taguchi, Y., Tsurukai, T., Tamura, M., Takahashi, N. and Suda, T. (1996) Osteoclast Function Is Activated by Osteoblastic Cells through a Mechanism Involving Cell-to-Cell Contact. Endocrinology, 137, 21872190 .

[9] Nicolin, V., Baldini, G., Bareggi, R., Zweyer, M., Zauli, G., Vaccarezza, M. and Narducci, P. (2006) Morphological Features of Osteoclasts Derived from a CoCulture System. Journal of Molecular Histology, 37, 171-177. https://doi.org/10.1007/s10735-006-9058-1

[10] Chang, K., Chang, W.H., Tsai, M.T. and Shih, C. (2006) Pulsed Electromagnetic Fields Accelerate Apoptotic Rate in Osteoclasts. Connective Tissue Research, 47, 222-228. https://doi.org/10.1080/03008200600858783

[11] Chang, K., Chang, W.H., Huang, S., Huang, S. and Shih, C. (2005) Pulsed Electromagnetic Fields Stimulation Affects Osteoclast Formation by Modulation of Osteoprotegerin, RANK Ligand and Macrophage Colonystimulating Factor. Journal of Orthopaedic Research, 23, 1308-1314.

[12] Tabrah, F.L., Ross, P., Hoffmeier, M. and Gilbert, J.F. (1998) Clinical Report on Long-Term Bone Density after Short-Term EMF Application. Bioelectromagnetics, 19, 75-78. https://doi.org/10.1002/(SICI)1521-186X(1998)19:2<75::AID-BEM3>3.0.CO;2-0

[13] Ibiwoye, M.O., Powell, K.A., Grabiner, M.D., Patterson, T.E., Sakai, Y., Zborowski, M., Wolfman, A. and Midura, R.J. (2004) Bone Mass Is Preserved in a Critical-Sized Osteotomy by Low Energy Pulsed Electromagnetic Fields as Quantitated by in Vivo Micro-Computed Tomography. Journal of Orthopaedic Research, 22, 1086-1093. https://doi.org/10.1016/j.orthres.2003.12.017

[14] Chen, J., He, H.C., Xia, Q.J., Huang, L.Q., Hu, Y.J. and He, C.Q. (2010) Effects of Pulsed Electromagnetic Fields on the mRNA Expression of RANK and CAII in Ovariectomized Rat Osteoclast-Like Cell. Connective Tissue Research, 51, 1-7. https://doi.org/10.3109/03008200902855917 
[15] Jian, C., Huang, L.Q., Xia, Q.J. and He, C.Q. (2012) Effects of Pulsed Electromagnetic Fields on the mRNA Expression of CAII and RANK in Ovariectomized Rats. Rheumatology International, 32, 1527-1532. https://doi.org/10.1007/s00296-010-1740-7

[16] Yokose, S., Ishizuya, T., Ikeda, T., Nakamura, T., Tsurukami, H., Kawasaki, K., Suda, T., Yoshiki, S. and Yamaguchi, A. (1996) An Estrogen Deficiency Caused by Ovariectomy Increases Plasma Levels of Systemic Factors That Stimulate Proliferation and Differentiation of Osteoblasts in Rats. Endocrinology, 137, 469-478.

[17] Idris, A.I., Rojas, J., Greig, I.R., Van't, H.R.J. and Ralston, S.H. (2008) Aminobisphosphonates Cause Osteoblast Apoptosis and Inhibit Bone Nodule Formation in Vitro. Calcified Tissue International, 82, 191-201. https://doi.org/10.1007/s00223-008-9104-y

[18] Ishizuya, T., Yokose, S., Hori, M., Noda, T., Suda, T., Yoshiki, S. and Yamaguchi, A. (1997) Parathyroid Hormone Exerts Disparate Effects on Osteoblast Differentiation Depending on Exposure Time in Rat Osteoblastic Cells. Journal of Clinical Investigation, 99, 2961-2970. https://doi.org/10.1172/JCI119491

[19] Chen, J., He, J.Q., Zhen, S.Y. and Huang, L. (2012) OPG Inhibits Gene Expression of RANK and CAII in Mouse Osteoclast-Like Cells. Rheumatology International, 32, 3393-3398. https://doi.org/10.1007/s00296-011-2338-4

[20] Aung, H.T., Schroder, K., Himes, S.R., Brion, K., Van, Z.W., Trieu, A., Suzuki, H., Hayashizaki, Y., Hume, D.A. and Sweet, M.J. (2006) LPS Regulates Proinflammatory Gene Expression in Macrophages by Altering Histone Deacetylase Expression. The FASEB Journal, 20, 1315-1327. https://doi.org/10.1096/fi.05-5360com

[21] Inoue, N.L., Ohnishi, I., Chen, D., Deitz. L.W., Schwardt, J.D. and Chao, E.Y.S. (2002) Effect of Pulsed Electromagnetic Fields (PEMF) on Late-Phase Osteotomy Gap Healing in a Canine Tibial Model. Journal of Orthopaedic Research, 20, 1106 1114. https://doi.org/10.1016/S0736-0266(02)00031-1

[22] Funk, RH. and Monsees, T.K. (2006) Effects of Electromagnetic Fields on Cells: Physiological and Therapeutical Approaches and Molecular Mechanisms of Interaction. A Review. Cells Tissues Organs, 182, 59-78. https://doi.org/10.1159/000093061

[23] Repacholi, M.H. and Greenebaum, B. (1999) Interaction of Static and Extremely Low Frequency Electric and Magnetic Fields with Living Systems: Health Effects and Research Needs. Bioelectromagnetics, 20, 133-160. https://doi.org/10.1002/(SICI)1521-186X(1999)20:3<133::AID-BEM1>3.0.CO;2-O

[24] Guerkov, H.H., Lohmann, C.H., Liu, Y., Dean, D.D., Simon, B.J., Heckman, J.D., Schwartz, Z. and Boyan, B.D. (2001) Pulsed Electromagnetic Fields Increase Growth Factor Release by Nonunion Cells. Clinical Orthopaedics and Related Research, 384, 265-279. https://doi.org/10.1097/00003086-200103000-00031

[25] Liboff, A.R., Williams, T., Strong, D.M. and Wistar, R. (1984) Time-Varying Magnetic-Fields-Effect on DNA-Synthesis. Science, 223, 818-820.

https://doi.org/10.1126/science.6695183

[26] Martin, T.J. and Sims, N.A. (2005) Osteoclast-Derived Activity in the Coupling of Bone Formation to Resorption. Trends in Molecular Medicine, 11, 76-81. https://doi.org/10.1016/j.molmed.2004.12.004

[27] Henriksen, K., Neutzsky-Wulff, A.V., Bonewald, L.F. and Karsdal, M.A. (2009) Local Communication on and within Bone Controls Bone Remodeling. Bone, 44, 10261033. https://doi.org/10.1016/j.bone.2009.03.671

[28] Liao, N., Chen, W., Huang, Y. and Chen, S. (2013) Research Propress of Co-Culture System of Osteoblast with Osteoclast and Its Applications. China Journal of Orthopaedics and Traumatology, 26, 349-353. 
Submit or recommend next manuscript to SCIRP and we will provide best service for you:

Accepting pre-submission inquiries through Email, Facebook, LinkedIn, Twitter, etc. A wide selection of journals (inclusive of 9 subjects, more than 200 journals)

Providing 24-hour high-quality service

User-friendly online submission system

Fair and swift peer-review system

Efficient typesetting and proofreading procedure

Display of the result of downloads and visits, as well as the number of cited articles Maximum dissemination of your research work

Submit your manuscript at: http://papersubmission.scirp.org/

Or contact jbise@scirp.org 